\title{
Female Carriers of Duchenne Muscular Dystrophy
}

Yu Na Cho and Young-Chul Choi*

Department of Neurology, Gangnam Severance Hospital, Yonsei University College of Medicine, Seoul, Korea

Dystrophinopathy, caused by mutations in the $D M D$ gene, presents with variable clinical phenotypes ranging from the severe Duchenne muscular dystrophy (DMD) to the milder Becker muscular dystrophy(BMD) forms. DMD is a recessive X-linked form of muscular dystrophy. Two-thirds of mothers of affected males are thought to be DMD carriers. Approximately 2.5-7.8\% of female DMD carriers have muscle weakness and are categorized as manifesting DMD carriers. The symptoms of female carriers of DMD range from mild muscle weakness to severe gait problems. The most commonly presented symptom is mild proximal muscle weakness, which is often asymmetric and progressive, but shows variable clinical spectrum with BMD of more severe DMD-like phenotype. Atypical presentations in manifesting carriers are myalgia or cramps without limb weakness, isolated cardiomyopathy and camptocormia. Multiplex PCR and MLPA analysis are common techniques to identify mutations in the $D M D$ gene. Relationship between $\mathrm{X}$-chromosome inactivation and clinical severity is not clear. Female carriers of DMD are not less common, and they have an important role of birth of a male DMD.

Key words: Dystrophinopathy, Duchenne muscular dystrophy, Female carrier, Multiplex ligation-dependent probe amplification

\section{Introduction}

Duchenne muscular dystrophy (DMD) is a recessive X-linked form of muscular dystrophy. The milder form of this disease is called Becker muscular dystrophy(BMD). ${ }^{1)}$ The disorder is also called dystrophinopathy because it caused by mutations in the DMD gene, which encodes dystrophin, on Xp21. ${ }^{2)}$ Most heterozygous female carriers of DMD are subclinical. Therefore, identification of dystrophinopathy carriers may be only considered on clinical grounds such as clear X-linked family history of muscular dystrophy. However, myopathic muscle biopsy and advanced molecular diagnostic analysis can be used to identify the carrier state of DMD without a positive family history of dystrophinopathy, which is present in 10\% of women with hyperCKemia. ${ }^{3)}$ In addition, two-thirds of mothers of affected males are thought to be DMD carriers. Approximately $2.5-7.8 \%$ of female DMD carriers have muscle weakness and are categorized as manifesting DMD carriers. ${ }^{1,24}$ Therefore, here we reviewed recent studies to meet the need for a better understanding about the characterization of female carriers of DMD.

\section{What is dystrophinopathies?}

Duchenne's description of DMD was published in 1861. He referred to the disease as "hypertrophic paraplegia of infancy due to a cerebral cause.5) However, in 1868, he performed muscle biopsies and recognized that it was of muscular origin. He proposed the criteria for diagnosing this disease and reported the results of muscle biopsy which showed replacement of muscle by fat and connective tissue. ${ }^{6}$ Gowers, in 1886, noted that cases

\footnotetext{
Received: 11 October 2013, Revised: 13 December 2013, Accepted: 20 December 2013, Published: 31 December 2013

${ }^{*}$ Corresponding author: Young-Chul Choi, M.D., Ph.D.

Department of Neurology, Brain Korea 21 Project for Medical Science, Yonsei University College of Medicine, 211 Eonjuro, Gangnam-gu, Seoul 135-720, Korea Tel: +82-2-2019-3323, Fax: +82-2-3462-5904, E-mail: ycchoi@yuhs.ac

Conflict of interest: We declare that we do not have any conflicts of interests.

(c) This is an open-access article distributed under the terms of the Creative Commons Attribution Non-Commercial License (http://creativecommons.org/licenses/by-nc/3.0/) which permits unrestricted non-commercial use, distribution, and reproduction in any medium, provided the original work is properly cited.

(c) Copyright 2013 by the Korean Society of Medical Genetics 
always occurred on the mother's side of the family. ${ }^{7)}$ Depending on the advancement of molecular genetics, mapping of the gene responsible for DMD was available to band p21 of the short arm of the $X$ chromosome (Xp21). ${ }^{8-11)}$ Subsequently, Kunkel's group identified the muscle protein dystrophin which is encoded by the DMD gene. ${ }^{12)}$ The full-size dystrophin is $427 \mathrm{kDa}$ in molecular mass ${ }^{12)}$ and its distribution is almost the same in both slow and fast fiber types. ${ }^{13)}$ In addition, the extent of dystrophin expression is associated with clinical severity of dystrophinopathy patients. ${ }^{13)}$ Dystrophin, located in the sarcolemma of muscle fibers, is almost absent in DMD and decreased in BMD. These advances were able to make diagnosis and genetic counseling more accurate.

\section{Dystrophinopathies in female patients}

Random inactivation of one of the two X chromosomes occurs during early embryonic development, leaving active $50 \%$ of the maternally derived chromosomes and 50\% of the paternally derived ones. ${ }^{14)}$ Non-random X-chromosome inactivation induce fewer than $50 \%$ of the nuclei which may have the normal dystrophin gene, resulting in clinical manifesting female carriers. ${ }^{15)}$ Some reports described cases of $X$-autosomal translocations with breakpoints at Xp21 resulting in preferential inactivation of the normal chromosome. ${ }^{8,11)}$ If the X chromosome of turner syndrome patient (karyotype $\mathrm{XO}$ ) carries a mutated dystrophin gene, her daughter can be symptomatic.

\section{Clinical presentation of female carrier of DMD}

DMD is the most common form of childhood muscular dystrophy, with an incidence of approximately 1 in 3,6006,000 live male births and a prevalence of approximately 3 per $100,000 .{ }^{16,17)}$ The symptoms of DMD female carriers range from mild muscle weakness to severe gait problems. Although manifesting girls usually show much milder symptoms than boys, a few cases have disease severity similar to that seen in affected boys. ${ }^{3{ }^{18,19)}}$ The most commonly presented symptom is mild proximal muscle weakness, which is often asymmetric and progressive. There are variable clinical patterns from BMD-like to severe DMD-like phenotype. ${ }^{20)}$ The prevalence of manifesting female carriers of DMD is slightly different in each study. Recent study reported 22\% of female carriers manifested the symptoms, with 19\% demonstrating muscle weakness measured by manual muscle testing and 8\% presenting with dilated cardiomyopathy. ${ }^{211}$ A similar prevalence of females with symptoms was observed by other group, with $12 \%$ presenting with muscle weakness and 7\% displaying cardiomyopathies. ${ }^{22)}$ Some manifesting carriers only present myalgia or cramps without limb weakness. ${ }^{23)}$ In addition, unusual cases such as isolated cardiomyopathy without skeletal muscle weakness ${ }^{24-26)}$ and developmental delay in childhood have been reported. ${ }^{23)}$ Also, there have been reports of manifesting carriers of DMD who initially presented with camptocormia which is forward flexion of the thoracolumbar spine that abates in the supine position. ${ }^{27)}$

\section{Imaging evaluation of female carrier of DMD}

Serum creatine kinase levels are commonly elevated in manifesting carriers of DMD. ${ }^{28)}$ Magnetic resonance imaging (MRI) is performed for more comprehensive assessment of muscles. There was a report about elevation of reported proton spin lattice relaxation time $\left(T_{1}\right)$ in female carriers elevated in the gluteals, vastus lateralis, and gastrocnemius compared with the control group and correlation with the distribution of muscle edema. ${ }^{29)}$ Elevated spin-spin or tranverse relaxation time $\left(T_{2}\right)$ in DMD carriers was also observed following muscle damage and inflammation/edema. ${ }^{30,311}$ Quantitative MRI measures were used to evaluate muscle composition. ${ }^{32)}$ In female carriers of $\mathrm{DMD}$, there was considerable heterogeneity among lipid fraction measures compared with the control groups during 21 months of a longitudinal study. ${ }^{32)}$ Although specific findings of imaging evaluation in female carriers of DMD has not yet been established, depending on the advance of neuroradiology, these invasive techniques could be strong tools for evaluation of carrier status.

Insights of diagnostic strategies of female carrier of DMD: diagnosis, novel pathological and genetic evidence

\section{Pathology}

Muscle biopsy is used for diagnosis in cases of clinically suspicious of dystrophinopathy. It can provide information about the amount and molecular size if the protein is present. Muscle biopsy is usually not necessary when genetic testing is positive. However, pathological evidence is helpful for patients with a family history of DMD, but no family mutation is known. ${ }^{18)}$

Dystrophin labeling of muscle biopsies from manifesting carriers 
shows a mosaic pattern, with reduced or absent dystrophin. ${ }^{33,34)}$ Immunohistochemistry findings are concordant with western blot analysis for dystrophin. ${ }^{34)}$ No association is seen between the pattern of distribution of dystrophin and clinical severity of manifesting carriers. ${ }^{35)}$ However, a few cases revealed that the absence of dystrophin expression and unstained fiber presumably affected the more severe phenotype. ${ }^{20)}$ Moreover, dystrophin expression can vary in different muscle groups of DMD carriers. ${ }^{36)}$

\section{Genetic test}

The dystrophin gene have majority of deletion mutation, approximately 61.9-73\% in western, northerm and Asian populations. ${ }^{37-39)}$ The frequency of deletions of the DMD gene is greater in affected males resulting from a female gametic mutation (75\%) than in those resulting from a male genetic mutation (56\%). ${ }^{40)} D M D$ gene partial duplications account for up to $6 \%$ of DMD and BMD cases. ${ }^{41)}$

Dystrophin mutation is able to be detected by Multiplex $\mathrm{PCR}^{42)}$ and multiplex ligation-dependent probe amplification (MLPA) ${ }^{43)}$

Multiplex PCR is a common technique to identify mutations of the $D M D$ gene and can detect approximately $98 \%$ of deletions. ${ }^{34)}$ Since multiplex PCR is the least expensive and sensitive method, it is the first method of choice by clinicians when the patient is highly suspicious of DMD. ${ }^{41)}$ Recently, several reports showed that MLPA is a more accurate method for mutation analysis of DMD than multiplex PCR. MLPA can detect the presence of deletions, duplication and abnormal DNA methylation. In particular, MLPA is the gold standard for molecular analysis of large number of genes. ${ }^{44)}$ Therefore, if the patient is clinically suspected of DMD or is a female carrier of DMD but shows negative results from multiplex PCR, MLPA is recommend for mutation analysis. ${ }^{45)}$ MLPA probes are sensitive to small changes within the sequence detected by the probe. A single nucleotide change very close to the probe ligation site can result in a decreased probe signal, thus mimicking a deletion. ${ }^{46)}$ Therefore, it is strongly recommended to confirm all MLPA findings with another method, especially in cases of single probe deletions. ${ }^{46,47)}$

Furthermore, dystrophin gene sequencing is used to analyze single-condition amplification/internal primers and multiplex amplifiable probe hybridization for detecting point mutations or small deletions/insertions if deletion/ duplication testing is negative. ${ }^{48,49)}$

Full characterisation of the mutation (deletion endpoints or exact position of any point mutation) is helpful to investigate the clinical variability of dystrophinopathy ${ }^{50,51)}$ and recent trials about mutation-specific treatment. . $^{52-54)}$

\section{X-chromosome inactivation (XCl)}

Symptomatic carriers of DMD without chromosomal rearrangements have been explained by skewed X-chromosome inactivation related to preferential expression of the mutant allele. ${ }^{36,55,56)}$ The nonrandom X-inactivation pattern of manifesting carriers of DMD showed derivative $X$ remaining active as a saving mechanism against disease-expression. ${ }^{11,57)}$ Therefore, the extent of X-chromosome inactivation skewing is correlated with clinical phenotype ${ }^{58)}$ Nevertheless, some studies reported no significant association between $\mathrm{X}$-chromosome inactivation pattern and clinical severity. ${ }^{59)}$ Prognostic value of $X$-chromosome inactivation is also controversial. ${ }^{58,60,61)}$

\section{Conclusion}

Female carriers of DMD are not less common, and they have an important role in male DMD. Comprehension of characterization of female carriers of DMD is helpful for establishment of diagnostic approaches in patients who may have in the past been diagnosed as having autosomal recessive limb-girdle muscular dystrophy or unknown myopathy with a negative family history.

\section{References}

1. Moser $\mathrm{H}$, Emery AE. The manifesting carrier in Duchenne muscular dystrophy. Clin Genet 1974;5:271-84.

2. Norman A, Harper P. A survey of manifesting carriers of Duchenne and Becker muscular dystrophy in Wales. Clin Genet 1989;36:31-7.

3. Hoffman EP, Arahata K, Minetti C, Bonilla E, Rowland LP. Dystrophinopathy in isolated cases of myopathy in females. Neurology 1992;42: 967-75.

4. Taylor PJ, Maroulis S, Mullan GL, Pedersen RL, Baumli A, Elakis G, et al Measurement of the clinical utility of a combined mutation detection protocol in carriers of Duchenne and Becker muscular dystrophy. J Med Genet 2007;44:368-72.

5. Duchenne GB. De l'électrisation localisée et de son application à la physiologie, à la pathologie et à la thérapeutique. 2nd Ed, Paris: Baillière, 1861.

6. Duchenne GB. De la paralysie musculaire pseudo-hypertrophique ou paralysie myo-sclérosique. Paris:P. Asselin, 1868.

7. Gowers WR. A manual of diseases of the nervous system. London: Churchill, 1886.

8. Greenstein RM, Reardon MP, Chan TS, Middleton AB, Mulivor RA, Greene $A E$, et al. $A n(X ; 11)$ translocation in a girl with Duchenne muscular 
dystrophy. Repository identification No. GM1695. Cytogenet Cell Genet 1980;27:268

9. Davies KE, Pearson PL, Harper PS, Murray JM, O'Brien T, Sarfarazi M, et al. Linkage analysis of two cloned DNA sequences flanking the Duchenne muscular dystrophy locus on the short arm of the human X chromosome. Nucleic Acids Res 1983;11:2303-12.

10. Francke $U$, Ochs HD, de Martinville B, Giacalone J, Lindgren V, Disteche $C_{1}$ et al. Minor Xp21 chromosome deletion in a male associated with expression of Duchenne muscular dystrophy, chronic granulomatous disease, retinitis pigmentosa, and McLeod syndrome. Am J Hum Genet 1985;37:250-67.

11. Boyd Y, Buckle V, Holt S, Munro E, Hunter D, Craig I. Muscular dystrophy in girls with X;autosome translocations. J Med Genet 1986;23:484-90.

12. Hoffman EP, Brown RH, Jr., Kunkel LM. Dystrophin: the protein product of the Duchenne muscular dystrophy locus. Cell 1987;51:919-28.

13. Culligan KG, Mackey AJ, Finn DM, Maguire PB, Ohlendieck K. Role of dystrophin isoforms and associated proteins in muscular dystrophy (review). Int J Mol Med 1998;2:639-48.

14. Matthews PM, Karpati G. Pattern of X-chromosome inactivation as a key determinant of the clinicopathologic phenotype of Duchenne muscular dystrophy carriers. Neurology 1996;46:1189-91.

15. Pena SD, Karpati G, Carpenter S, Fraser FC. The clinical consequences of $\mathrm{X}$-chromosome inactivation: Duchenne muscular dystrophy in one of monozygotic twins. J Neurol Sci 1987;79:337-44.

16. Bushby K, Finkel R, Birnkrant DJ, Case LE, Clemens PR, Cripe $L$, et al. Diagnosis and management of Duchenne muscular dystrophy, part 1: diagnosis, and pharmacological and psychosocial management. Lancet Neurol 2010;9:77-93.

17. Emery AE. Population frequencies of inherited neuromuscular diseases-a world survey. Neuromuscul Disord 1991;1:19-29.

18. Bushby KM, Goodship JA, Nicholson LV, Johnson MA, Haggerty ID, Gardner-Medwin D. Variability in clinical, genetic and protein abnormalities in manifesting carriers of Duchenne and Becker muscular dystrophy. Neuromuscul Disord 1993;3:57-64.

19. Richards CS, Watkins SC, Hoffman EP, Schneider NR, Milsark IW, Katz $\mathrm{KS}$, et al. Skewed X inactivation in a female MZ twin results in Duchenne muscular dystrophy. Am J Hum Genet 1990;46:672-81.

20. Soltanzadeh P, Friez MJ, Dunn D, von Niederhausern A, Gurvich OL, Swoboda KJ, et al. Clinical and genetic characterization of manifesting carriers of DMD mutations. Neuromuscul Disord 2010;20:499-504.

21. Hoogerwaard EM, Bakker E, Ippel PF, Oosterwijk JC, Majoor-Krakauer DF, Leschot NJ, et al. Signs and symptoms of Duchenne muscular dystrophy and Becker muscular dystrophy among carriers in The Netherlands: a cohort study. Lancet 1999;353:2116-9.

22. Grain L, Cortina-Borja M, Forfar C, Hilton-Jones D, Hopkin J, Burch M. Cardiac abnormalities and skeletal muscle weakness in carriers of Duchenne and Becker muscular dystrophies and controls. Neuromuscul Disord 2001;11:186-91.

23. Ceulemans BP, Storm K, Reyniers E, Jr., Callewaert L, Martin JJ. Muscle pain as the only presenting symptom in a girl with dystrophinopathy. Pediatr Neurol 2008;38:64-6.

24. Kinoshita $H$, Goto $Y$, Ishikawa $M$, Uemura T, Matsumoto $K$, Hayashi YK, et al. A carrier of Duchenne muscular dystrophy with dilated cardiomyopathy but no skeletal muscle symptom. Brain Dev 1995;17: 202-5.

25. Mirabella M, Servidei S, Manfredi G, Ricci E, Frustaci A, Bertini E, et al. Cardiomyopathy may be the only clinical manifestation in female carriers of Duchenne muscular dystrophy. Neurology 1993;43:2342-5.

26. Walcher $T$, Kunze $M$, Steinbach $P$, Sperfeld AD, Burgstahler $C_{1}$ Hombach $\checkmark$, et al. Cardiac involvement in a female carrier of Duchenne muscular dystrophy. Int J Cardiol 2010;138:302-5.

27. Findlay AR, Lewis S, Sahenk Z, Flanigan KM. Camptocormia as a late presentation in a manifesting carrier of duchenne muscular dystrophy. Muscle Nerve 2013;47:124-7.

28. Griggs RC, Mendell JR, Brooke MH, Fenichel GM, Miller JP, Province M, et al. Clinical investigation in Duchenne dystrophy: V. Use of creatine kinase and pyruvate kinase in carrier detection. Muscle Nerve 1985;8:60-7.

29. Matsumura K, Nakano I, Fukuda N, Ikehira H, Tateno Y, Aoki Y. Duchenne muscular dystrophy carriers. Proton spin-lattice relaxation times of skeletal muscles on magnetic resonance imaging. Neuroradiology 1989;31:373-6.

30. Foley JM, Jayaraman RC, Prior BM, Pivarnik JM, Meyer RA. MR measurements of muscle damage and adaptation after eccentric exercise. J Appl Physiol (1985) 1999;87:2311-8.

31. Mathur S, Vohra RS, Germain SA, Forbes $S$, Bryant ND, Vandenborne $K_{\text {, }}$ et al. Changes in muscle 22 and tissue damage after downhill running in mdx mice. Muscle Nerve 2011;43:878-86.

32. Forbes SC, Lott DJ, Finkel RS, Senesac C, Byrne BJ, Sweeney HL, et al. MRI/ MRS evaluation of a female carrier of Duchenne muscular dystrophy. Neuromuscul Disord 2012;22 Suppl 2:S111-21.

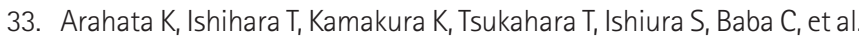
Mosaic expression of dystrophin in symptomatic carriers of Duchenne's muscular dystrophy. N Engl J Med 1989;320:138-42.

34. Na SJ, Kim WJ, Kim SM, Lee KO, Yoon B, Choi YC. Clinical, immunohistochemical, Western blot, and genetic analysis in dystrophinopathy. J Clin Neurosci 2013;20:1099-105.

35 Hoogerwaard EM, Ginjaar IB, Bakker E, de Visser M. Dystrophin analysis in carriers of Duchenne and Becker muscular dystrophy. Neurology 2005;65:1984-6.

36. Azofeifa J, Voit T, Hubner $C_{1}$ Cremer M. X-chromosome methylation in manifesting and healthy carriers of dystrophinopathies: concordance of activation ratios among first degree female relatives and skewed inactivation as cause of the affected phenotypes. Hum Genet 1995;96: 167-76.

37. Singh V, Sinha S, Mishra S, Chaturvedi LS, Pradhan S, Mittal RD, et al. Proportion and pattern of dystrophin gene deletions in north Indian Duchenne and Becker muscular dystrophy patients. Hum Genet 1997:99:206-8. 
38. Lai PS, Takeshima Y, Adachi K, Van Tran K, Nguyen HT, Low PS, et al. Comparative study on deletions of the dystrophin gene in three Asian populations. J Hum Genet 2002;47:552-5.

39. Khalap N, Joshi V, Ladiwalla U, Khadilkar S, Mahajan S. A report on higher frequency of DMD gene deletion in the Indian subcontinent. Indian J Hum Genet 1997;3:117-20.

40. Baumbach LL, Chamberlain JS, Ward PA, Farwell NJ, Caskey CT. Molecular and clinical correlations of deletions leading to Duchenne and Becker muscular dystrophies. Neurology 1989;39:465-74.

41. Hu X, Ray PN, Murphy EG, Thompson M, Worton R. Duplicational mutation at the Duchenne muscular dystrophy locus: its frequency, distribution, origin, and phenotypegenotype correlation. Am J Hum Genet 1990;46:682-95.

42. Prior TW, Bridgeman SJ. Experience and strategy for the molecular testing of Duchenne muscular dystrophy. J Mol Diagn 2005;7:317-26.

43. Lalic T, Vossen RH, Coffa J, Schouten JP, Guc-Scekic M, Radivojevic D, et al. Deletion and duplication screening in the DMD gene using MLPA. Eur J Hum Genet 2005;13:1231-4.

44. Stuppia L, Antonucci I, Palka G, Gatta V. Use of the MLPA Assay in the Molecular Diagnosis of Gene Copy Number Alterations in Human Genetic Diseases. Int J Mol Sci 2012;13:3245-76.

45. Song TJ, Lee KA, Kang SW, Cho H, Choi YC. Three cases of manifesting female carriers in patients with Duchenne muscular dystrophy. Yonsei Med J 2011;52:192-5.

46. Cho H, Hong JM, Lee KA, Choi YC. Clinical usefulness of molecular diagnosis in dystrophin gene mutations using the multiplex ligationdependent probe amplification (MLPA) method. J Korean Neurol Assoc 2010;28:22-6.

47. Sellner LN, Taylor GR. MLPA and MAPH: new techniques for detection of gene deletions. Hum Mutat 2004;23:413-9.

48. Flanigan KM, von Niederhausern A, Dunn DM, Alder J, Mendell JR, Weiss RB. Rapid direct sequence analysis of the dystrophin gene. Am J Hum Genet 2003;72:931-9.

49. Dent KM, Dunn DM, von Niederhausern AC, Aoyagi AT, Kerr L, Bromberg $M B$, et al. Improved molecular diagnosis of dystrophinopathies in an unselected clinical cohort. Am J Med Genet A 2005;134:295-8.

50. Yasuma F, Konagaya M, Sakai M, Kuru S, Kawamura T. A new lease on life for patients with Duchenne muscular dystrophy in Japan. Am J Med 2004;117:363.
51. Jeppesen J, Green A, Steffensen BF, Rahbek J. The Duchenne muscular dystrophy population in Denmark, 1977-2001: prevalence, incidence and survival in relation to the introduction of ventilator use. Neuromuscul Disord 2003;13:804-12.

52. Lim LE, Rando TA. Technology insight: therapy for Duchenne muscular dystrophy-an opportunity for personalized medicine? Nat Clin Pract Neurol 2008;4:149-58.

53. van Ommen GJ, van Deutekom J, Aartsma-Rus A. The therapeutic potential of antisense-mediated exon skipping. Curr Opin Mol Ther 2008;10:140-9.

54. van Deutekom JC, Janson AA, Ginjaar IB, Frankhuizen WS, Aartsma-Rus $A$, Bremmer-Bout $M$, et al. Local dystrophin restoration with antisense oligonucleotide PRO051. N Engl J Med 2007;357:2677-86.

55. Yoshioka M, Yorifuji T, Mituyoshi I. Skewed X inactivation in manifesting carriers of Duchenne muscular dystrophy. Clin Genet 1998;53:102-7.

56. Pegoraro E, Schimke RN, Arahata K, Hayashi Y, Stern H, Marks H, et al. Detection of new paternal dystrophin gene mutations in isolated cases of dystrophinopathy in females. Am J Hum Genet 1994;54:989-1003.

57. Wenger SL, Steele MW, Hoffman EP, Barmada MA, Wessel HB. X inactivation and dystrophin studies in a $t(X ; 12)$ female: evidence for biochemical normalization in Duchenne muscular dystrophy carriers. Am J Med Genet 1992;43:1012-5.

58. Juan-Mateu J, Rodriguez MJ, Nascimento A, Jimenez-Mallebrera C, Gonzalez-Quereda L, Rivas $E_{1}$ et al. Prognostic value of X-chromosome inactivation in symptomatic female carriers of dystrophinopathy. Orphanet J Rare Dis 2012;7:82.

59. Brioschi S, Gualandi F, Scotton C, Armaroli A, Bovolenta M, Falzarano $M S$, et al. Genetic characterization in symptomatic female DMD carriers: lack of relationship between $\mathrm{X}$-inactivation, transcriptional DMD allele balancing and phenotype. BMC Med Genet 2012;13:73.

60. Matthews PM, Benjamin D, Van Bakel I, Squier MV, Nicholson LV, Sewry

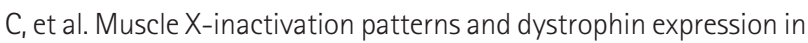
Duchenne muscular dystrophy carriers. Neuromuscul Disord 1995;5: 209-20.

61. Sumita DR, Vainzof $M$, Campiotto $S$, Cerqueira AM, Canovas M, Otto PA, et al. Absence of correlation between skewed Xinactivation in blood and serum creatine-kinase levels in Duchenne/Becker female carriers. Am J Med Genet 1998;80:356-61. 